\title{
Trauma Surgery \& Acute Care Open \\ Staying connected: Service-specific orientation can be successfully achieved using a mobile application for onboarding care providers
}

\author{
Kristen M Chreiman, ${ }^{1}$ Priya S Prakash, ${ }^{1}$ Niels D Martin, ${ }^{1}$ Patrick K Kim, ${ }^{1}$ \\ Samir Mehta, ${ }^{2}$ Kelly McGinnis, ${ }^{2}$ John J Gallagher, ${ }^{1}$ Patrick M Reilly ${ }^{1}$
}

${ }^{1}$ Division of Traumatology, Surgical Critical Care and Emergency Surgery, University of Pennsylvania, Pennsylvania, USA

${ }^{2}$ Department of Orthopaedic Surgery, University of Pennsylvania, Pennsylvania, USA

\section{Correspondence to}

Kristen M Chreiman, Division of Trauma, Surgical Critical Care and Emergency Surgery, University of Pennsylvania, Penn Presbyterian Medical Center, 51N 39th Street Suite 120 MOB, Philadelphia,

PA 19104, USA;

Kristen.chreiman@uphs.upenn. edu

Received 17 February 2017 Accepted 13 March 2017

To cite: Chreiman $\mathrm{KM}$ Prakash PS, Martin ND, et al. Trauma Surg Acute Care Open Published Online First: [please include Day Month Year] doi:10.1136/ tsaco-2017-000085

\section{ABSTRACT}

Communicating service-specific practice patterns, guidelines, and provider information to a new team of learners that rotate frequently can be challenging. Leveraging individual and healthcare electronic resources, a mobile device platform was implemented into a newly revised resident onboarding process. We hypothesized that offering an easy-to-use mobile application would improve communication across multiple disciplines as well as improve provider experiences when transitioning to a new rotation. A mobile platform was created and deployed to assist with enhancing communication within a trauma service and its resident onboarding process. The platform had resource materials such as: divisional policies, Clinical Practice Guidelines (CMGs), and onboarding manuals along with allowing for the posting of divisional events, a divisional directory that linked to direct dialing, text or email messaging, as well as on-call schedules. A mixedmethods study, including an anonymous survey, aimed at providing information on team member's impressions and usage of the mobile application was performed. Usage statistics over a 3-month period were analyzed on those providers who completed the survey. After rotation on the trauma service, trainees were asked to complete an anonymous, online survey addressing both the experience with, as well as the utility of, the mobile app. Thirty of the $37(81 \%)$ residents and medical students completed the survey. Twenty-five (83\%) trainees stated that this was their first experience rotating on the trauma service and $6(20 \%)$ were from outside of the health system. According to those surveyed, the most useful function of the app were access to the directory $(15,50 \%)$, the divisional calendar $(4,13.3 \%)$, and the on-call schedules (3, $10 \%)$. Overall, the app was felt to be easy to use (27, $90 \%$ ) and was accessed an average of 7 times per day (1-50, SD 9.67). Over half the survey respondents felt that the mobile app was helpful in completing their everyday tasks $(16,53.3 \%)$. Fifteen $(50 \%)$ of the respondents stated that the app made the transition to the trauma service easier. Twenty-five (83.3\%) stated it was valuable knowing about departmental events and announcements, and 17 (56.7\%) felt more connected to the division. The evolution of mobile technology is rapidly becoming fundamental in medical education and training. We found that integrating a service-specific mobile application improved the learner's experience when transitioning to a new service and was a valuable onboarding instrument.

Level of evidence IV.

\section{INTRODUCTION}

A new era of medicine, characterized by the integration of mobile devices into medical practice, is changing how medical education is structured..$^{12}$ Along with the evolution of medical apps, medical schools and clinical training programs are fostering the use of mobile devices for education as well as daily clinical activities. ${ }^{3}{ }^{4}$ Recent research has also proposed that implementation of mobile devices and associated apps have led to increased productivity and access to clinical information. ${ }^{5-8}$ Though the employment of mobile devices have been associated with improvements in resident efficiency and productivity, it has not been well studied as a tool to improve transitions to a new service and resident onboarding. $^{7} 9$

In a digital survey examining smartphones and associated app use of ACGME training programs nationally, Franko and Tirrell found that $>85 \%$ of respondents used a smartphone and half reported using apps in their clinical practice. They reported that residents had a greater desire for mobile applications that linked with medical training. ${ }^{10}$ Though there is a desire for mobile device adoption among trainees, there remains a mismatch between users' desires, existing software, and actual practice. ${ }^{11}$

Leveraging the prevalence of smartphones and the utility of a uniquely designed mobile application, we sought to assess and characterize the value of such technology in improving service connectedness and integrating trainees onto a new team. We hypothesized that offering an easy-to-use mobile application would improve communication as well as improve resident experiences when transitioning to a new rotation.

\section{METHODS}

A new mobile app platform was designed and customized using an app builder service known as Group Ahead (http://www.groupahead.com/). The platform allowed for the posting of divisional events, a divisional directory that linked to direct dialing, text or email messaging as well as links to the on-call schedule and resource materials such as divisional policies, Clinical Practice Guidelines (CMGs), and the resident onboarding manual.

Along with the implementation of the mobile app, the resident orientation process was restructured. An email was sent to residents, prior to the start of their rotation, with an onboarding packet which included links to the mobile app as well as a 
resident orientation checklist which defined topics to be covered on the first day of service, all of which could be pre-reviewed via the app. In addition, the residents and students were shown how to access, download, and use the functions of the mobile app at the start of their rotation.

At the completion of the rotation, residents were requested to voluntarily participate in an anonymous online survey ${ }^{12}$ to examine their experience using the mobile app. The surveys were administered over a 3-month period, gathering data through the use of a Likert scale, on user demographics, perceptions of improved knowledge of divisional events, team engagement, access to resources, and overall value of the mobile app in relation to performance on the service. Additionally, app usage data were available via the service provider. Descriptive statistics were used to interpret the data. The study was exempt from the Institutional Review Board.

\section{RESULTS}

Of the 37 trainees that rotated on the trauma service through the months of July, August, and September 2016, 30 completed the online survey, for an $81 \%$ response rate. Of the 30 respondents, 8 (26.7\%) were medical students, 15 (50\%) were either a postgraduate year (PGY) 1 or 2 , and 7 (23.3\%) were a PGY 3 or above. The subspecialties rotating on service included trauma and surgical critical care, orthopedic surgery, general surgery, neurosurgery, oral facial and maxillary surgery, and emergency medicine. Twenty-five (83\%) trainees stated that this was their first experience rotating on the trauma service and 6 (20\%) were from an institution outside the health system. Figure 1 lists the demographics of the trainees surveyed. Among those surveyed, the app was accessed an average of seven times a day (1-50, SD 9.67). Overall, the app was felt to be easy to use $(27,90 \%)$. Over half the survey respondents felt that the mobile app was helpful in completing their everyday tasks (16, $53.3 \%)$. The most useful functions of the app were access to the directory $(15,50 \%)$, to the divisional calendar $(4,13.3 \%)$, and to the on-call schedules (3,10\%; figure 2$)$. One (3.3\%) survey respondent felt that the references and links were the most useful. Fifteen $(50 \%)$ of the respondents stated that the app made the transition to the trauma service easier, $25(83.3 \%)$ stated it was valuable in knowing about departmental events and announcements, and $17(56.7 \%)$ felt more connected to the
Figure 1 Describes the demographics of the trainees surveyed. PGY, postgraduate year.

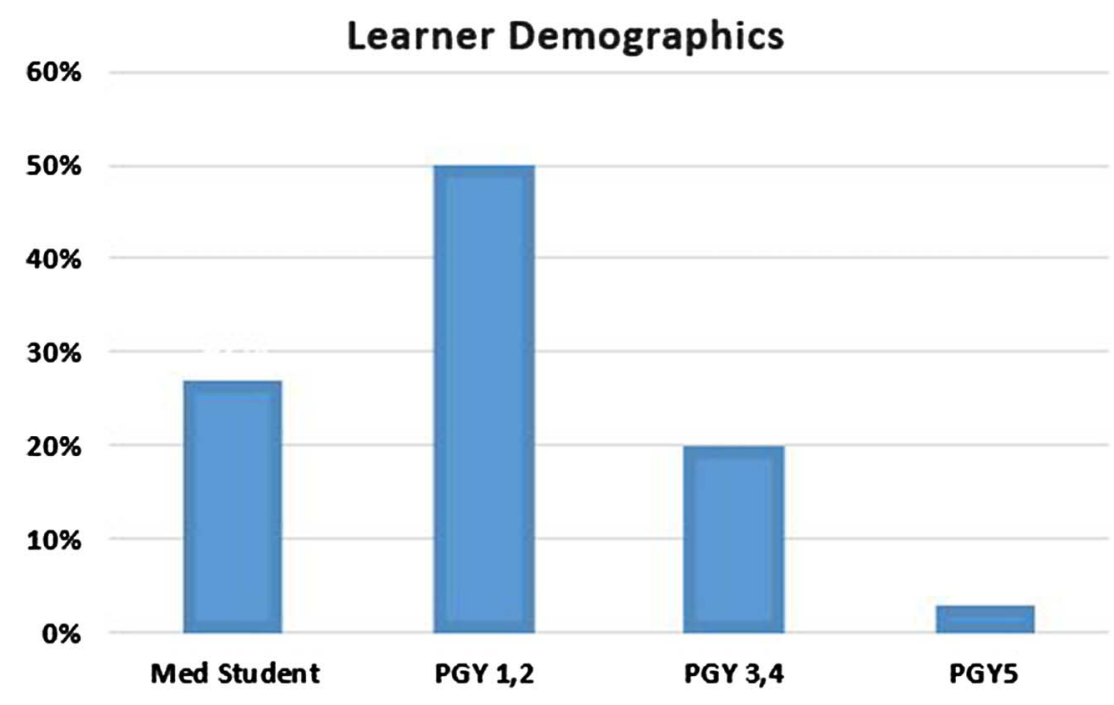

Mobile Application Usage During Study Period

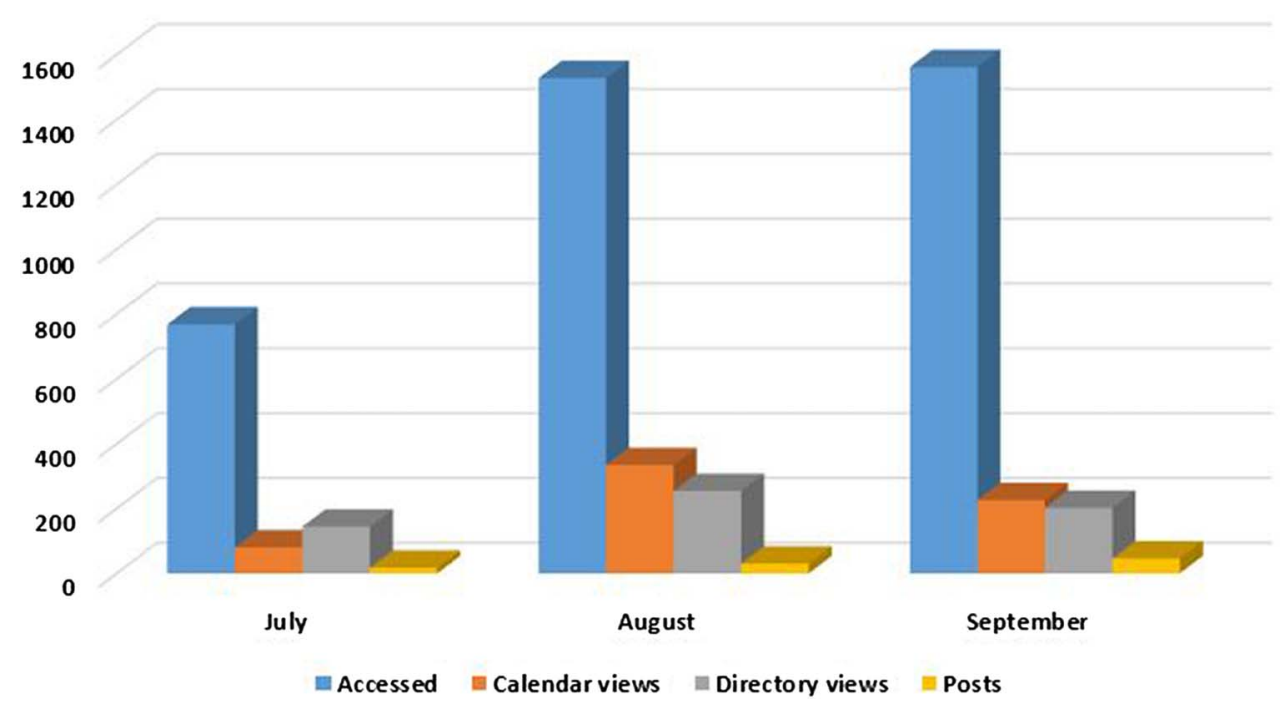

Figure 2 Describes the number of times the mobile app was accessed overall, number of clicks on the calendar and directory tabs, and the number of posts during the study period. 
division. Overall, the mobile app was viewed as a positive addition to the trauma service with $24(80 \%)$ trainees responding that the app was a valuable resource (figure 3 ).

During the study period, the number of times the app was accessed increased $49 \%$. This may be attributed to an increased number of posts some of which included notifications about new divisional events and publications. The trauma service orientation appeared to be the most used avenue to inform trainees about the mobile app (24, 80\%). Five (16.6\%) learned about the app from other residents or word of mouth and 1 (3.3\%) from the onboarding manual. Twenty-two (73.3\%) trainees stated they had received a tutorial on how to use the app.

\section{DISCUSSION}

Smartphones and usage of mobile applications have infiltrated healthcare systems, ${ }^{8} 101314$ creating a new era of medicine known as 'mHealth'. ${ }^{15}$ According to a recent study by Ellaway et al, physicians are expanding the use of mobile devices to support professional development and medical education. The advantage of integrating a smartphone app into medical education and training is the immediacy of accessing information at the time it is desired. ${ }^{1} 1314 \quad 16-19$ This capability is especially valuable to the Generation Y learner. ${ }^{20} 21$ Recent literature describes educating this generation in smaller groups and with varying teaching modalities. ${ }^{20} 21$ This would include incorporating didactic, and directed self-learning activities via technology such as videos, podcasts and simulations. Implementing a mobile app and redesigning the orientation structure to include service-specific didactic, simulation of the primary and secondary survey, hands on skills of hemorrhage control devices, computer training and orientation to the app was well received. The challenge continues to be determining the best way to engage and connect multiple generations to the app's utility, availability and location. 92021
The purpose of this study was to determine the value of integrating a customized mobile app to onboard residents to a new service. The results demonstrate that adoption of a mobile app was not only successful, but was felt to be a valuable tool while on the trauma team, assisting team members with transitioning to a new service and improving intradepartmental connectedness. Half of the survey respondents felt that the mobile app assisted in improving the transition to a new service. In addition, the majority of team members stated that the app was a valuable tool in providing knowledge about departmental events and announcements. One trainee commented "Having access to the trauma app as a visiting student quickly oriented me to the department. It made me aware of ongoing events." Over half of the survey respondents felt more connected to the division through the app. Overall, the mobile app was viewed as a positive addition to the trauma service with $80 \%$ of trainees responding that the app was a valuable resource. One of the benefits of this mobile application was the familiarity of the social media feel and functions (figure 5). The ability for any member to post professional events or educational opportunities enhanced engagement and was reflected in the results demonstrating connectedness. This was demonstrated by the $39 \%$ increase in postings and $49 \%$ increase in opening of the app from the beginning to the end of the study period (figure 2 and figure 4). Encouraging digital immigrants to participate and demonstrating value and ease of use to these late adopters remains a challenge. ${ }^{21}$

When determining the most useful features of the app, trainees felt that access to the directory, to the divisional calendar, and to the on-call schedules were most valuable, supporting that the mobile app was beneficial in improving departmental communication and connectedness (figures 2 and 3 and figure 5). Interestingly, only one survey respondent felt that the references and links were the most useful tool offered through the app. It

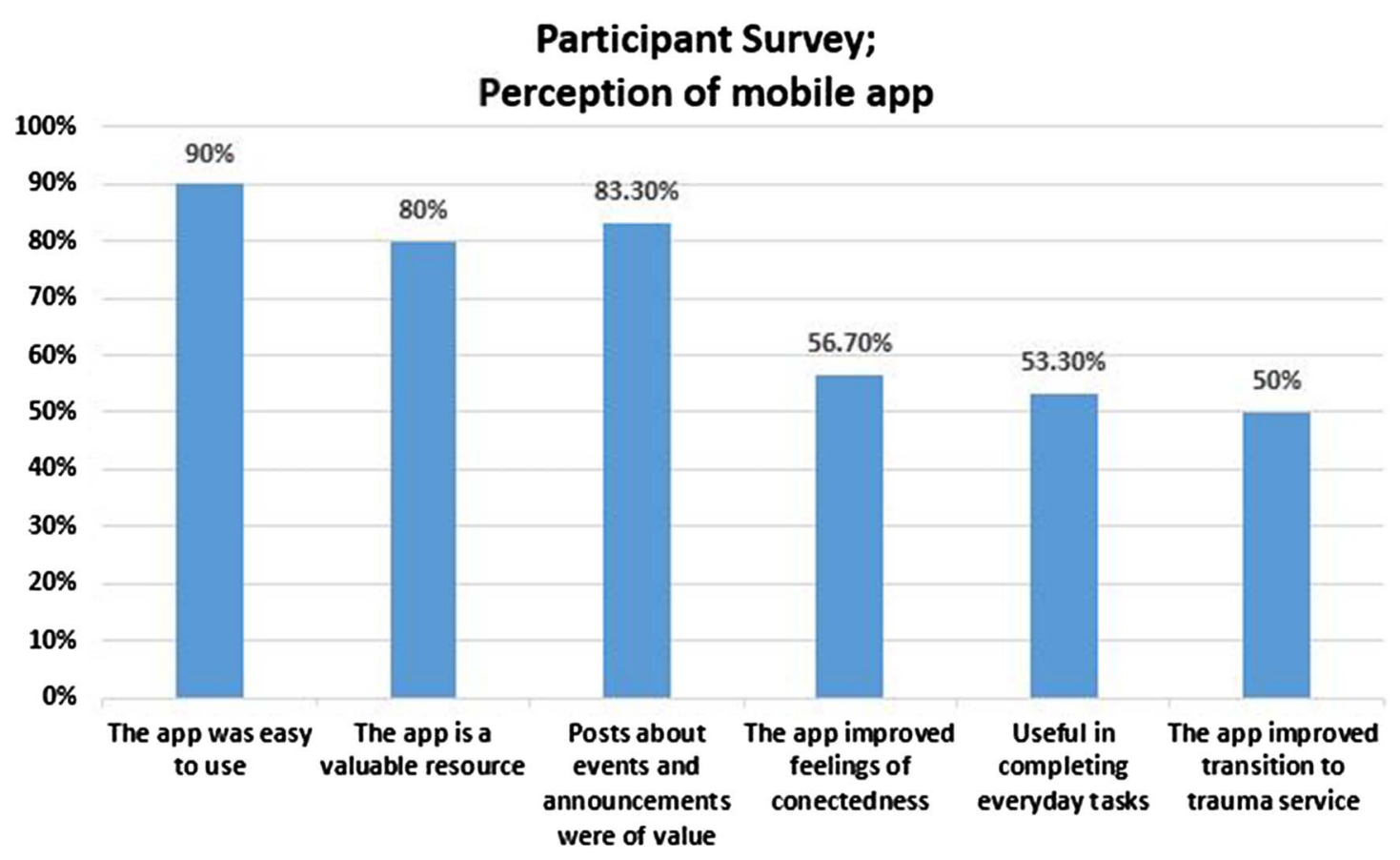

Figure 3 Describes the participant's perception of the mobile app's ease of use, value as a resource, value of the divisional posts, app's ability to improve feelings of connectedness to the division, app's usefulness in completing tasks and the perception of its ability to assist in the transition onto the service. 


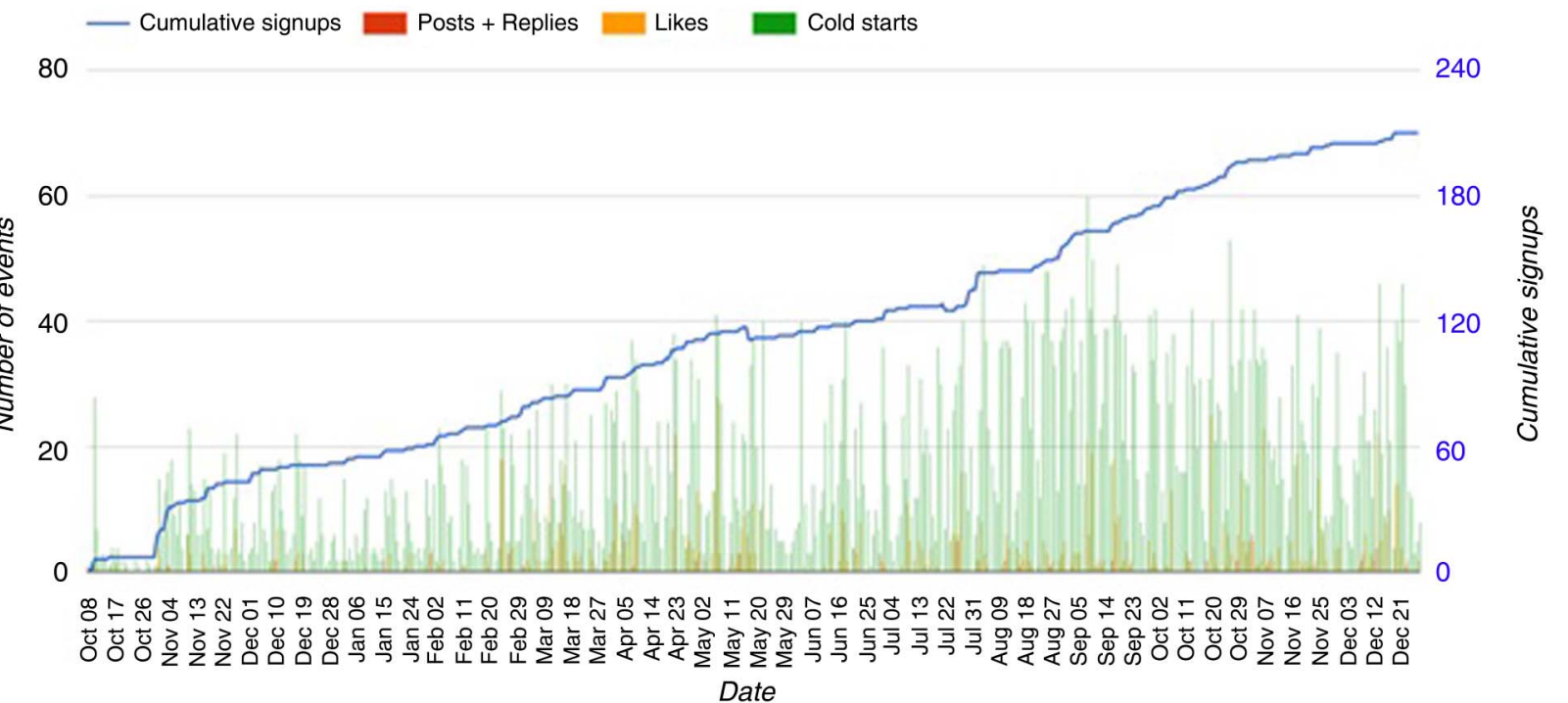

Figure 4 Demonstrates the number of signups, posts+replies (individual posts and comments), likes, and cold starts (the number of unique people that opened the app at least once that day).

\section{App Features: Posts, Calendar, Directory Links}
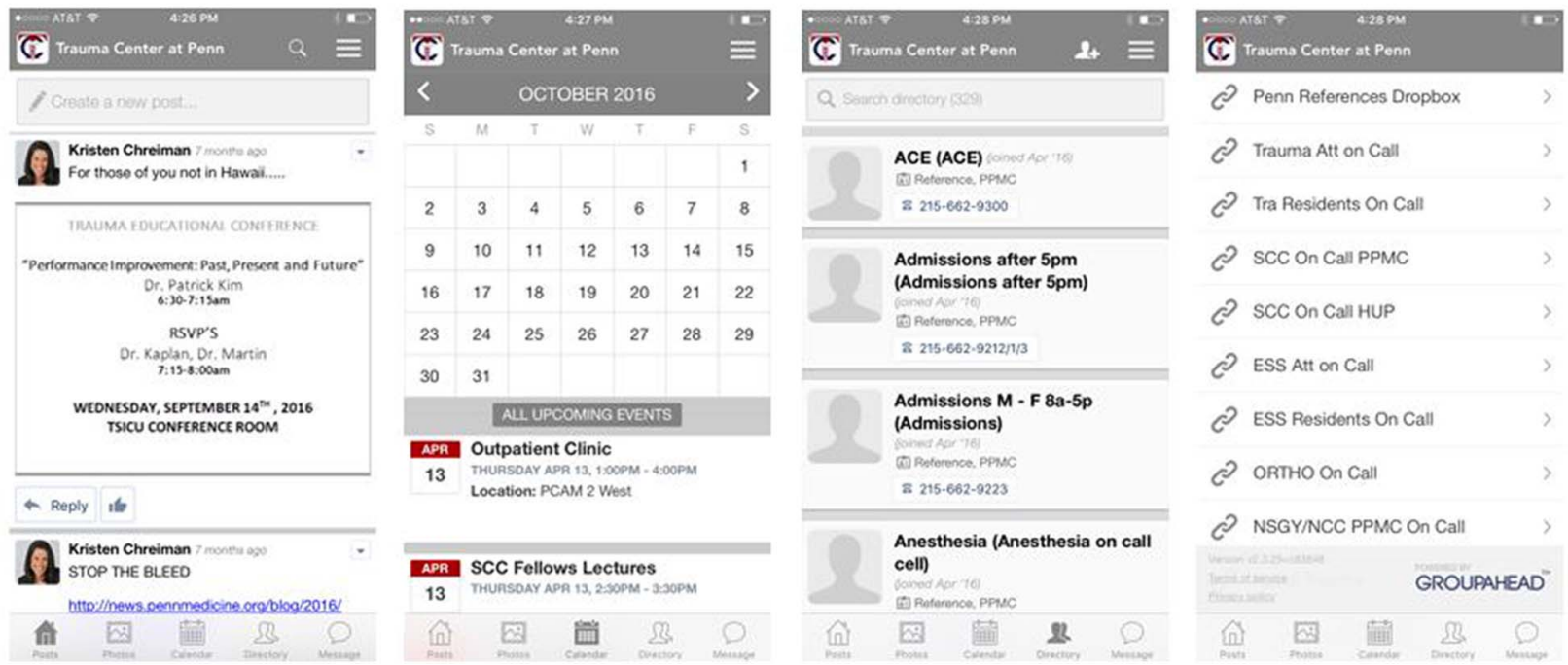

Figure 5 Features of the app include tabs (from left to right) for posting events, the divisional calendar of events, the trauma center directory, and external links to on-call schedules/references materials.

is unclear why this is, as it would be expected that in the age of electronic medical records and keeping current with best practices, trainees desire immediate and easy access to information. How to best integrate access to references, links, and other educational resources using a mobile platform requires further investigation. It is the opinion of the researchers that resident's responsibility for verifying their knowledge of division-specific CMGs varies, and may account for the lack of access to these links. Another possible confounding factor may be that there are too many clicks required to access the information and streamlining this process should be considered.

Though the mobile app was deemed a valuable tool by users, integration into daily practice initially exhibited a challenge. While transitioning from a traditional intranet accessible computer-based model to a more centralized mobile-friendly platform increased $49 \%$ among practitioners over the study period, consistent integration into daily practice took time. A potential solution to these challenges was incorporating an introduction to the mobile app during the service orientation. ${ }^{21}$ The resident onboarding process was re-engineered to mitigate variation by steering away from self-orientation and incorporating a more formalized process, which included orientation on how to access, download, and use features of the mobile app. ${ }^{20}{ }^{21}$ Even though introduction to the mobile app was formalized during the service orientation, $20 \%$ of trainees stated that they learned about the app elsewhere and almost 30\% stated they were not given tutorial on how to use the app. Though the majority of trainees felt that they did receive an 
in-servicing with the new technology, there is still the opportunity to improve the onboarding process and increase team member awareness of the educational tools and resources available.

Traditionally, surgical rotations provided little formal servicespecific orientation processes. Formalizing onboarding processes is a fairly recent practice. With increasing complexity of service lines and practitioners located at multiple campuses along with work-hours regulations, a new approach to interdepartmental and intradepartmental communication and resident onboarding is needed. A mobile app is one effective tool in addressing this gap. Creating innovative ways for knowledge development that is not time or schedule prohibited may improve trainee engagement, expand learning opportunities, and increase compliance with departmental clinical practice guidelines. In order to adapt to the learning preferences of a new generation of residents, many of whom digital natives, it is important to provide information that is mobile and electronic. ${ }^{21}$ Combining portability with an engaging self-directed learning format is the logical next step in education, and one way to approach this is with a customized mobile app.

\section{STUDY LIMITATIONS}

It should be recognized that some technology-based issues may have attributed to study limitations. Surgical residents not carrying the service-specific mobile phone only had access to the mobile app by downloading it to their personal device. In some instances, the resident's mobile device had limited storage capacity making the download unsuccessful unless enough free space was acquired. Although connectivity issues were not reported, users not synced to the hospital wifi or VPN were unable to link to the hospital's published on-call schedules from the app. Also, those using a personal mobile device required an additional free mobile app to access the reference material from a shared drop box link.

\section{FUTURE DIRECTIONS}

Future considerations include further prioritizing content of the reference materials. It is easy to fall into a trap of information overload. Ensuring that all information is relevant, up-to-date and can be easily accessible with limited clicks is challenging. Determining how faculty and fellows use the same accessible mobile resources would be a next step for future research. Adding service-specific video lectures, video orientation for residents starting on night or weekends and linking those to CMEs would enhance the usefulness of the mobile app. Shared knowledge with outside institutions may also be pivotal to all parties to enhance clinical care.

\section{CONCLUSION}

The evolution of mobile technology and smartphones is rapidly becoming fundamental in medical education, transforming a personal device into a professional tool. ${ }^{10}{ }^{22-25}$ Our study revealed that integrating a service-specific mobile application improved trainee experience when transitioning to a new service creating a valuable onboarding instrument. Choosing a platform that reliably serves the needs of a new generation of learners, is intuitive, and is easily manageable can improve expeditious access to pertinent information, communication and ameliorate onboarding processes. Reimagining a standardized resident onboarding process that uses a mobile application which includes access to service-specific events and educational references has the potential to mitigate variations in care and improve team connectedness. ${ }^{20-22}$

Contributors KMC and PSP were involved in concept, design, data, interpretation, writing, critical revision, and final approval. NDM was involved in design, survey development and interpretation, critical revision, and final approval. PKK was involved in design, survey development, critical revision, and final approval. SM was involved in concept, development of app, critical revision and final approval. KM was involved in concept, development of app, writing, and final approval. JJG was involved in design, critical revisions and final approval. PMR was involved in design, oversight, data interpretation, critical revisions, and final approval.

Competing interests None declared.

Ethics approval IRB ruling was exemption.

Provenance and peer review Not commissioned; externally peer reviewed.

Data sharing statement The authors agree to allow the corresponding authors to correspond with the editorial office, to review the uncorrected proof copy of the manuscript and to make decisions regarding release of information in the manuscript.

Open Access This is an Open Access article distributed in accordance with the Creative Commons Attribution Non Commercial (CC BY-NC 4.0) license, which permits others to distribute, remix, adapt, build upon this work non-commercially, and license their derivative works on different terms, provided the original work is properly cited and the use is non-commercial. See: http://creativecommons.org/ licenses/by-nc/4.0/

\section{REFERENCES}

1 Collins F. How to fulfill the true promise of "mHealth": mobile devices have the potential to become powerful medical tools. Sci Am 2012;307:16

2 Peck AD. App-solutely fabulous. hundreds of new apps for IPAD and tablets make mHealth a reality and a lifestyle choice. Med Econ 2011;88:S11-14.

3 Berkowitz SJ, Kung JW, Eisenberg RL, Donohoe K, Tsai LL, Slanetz PJ. Resident iPad use: has it really changed the game? J Am Coll Radiol 2014;11:180-4.

4 George P, Dumenco L, Dollase R, Taylor JS, Wald HS, Reis SP. Introducing technology into medical education: two pilot studies. Patient Educ Couns 2013:93:522-4

5 Goldbach $\mathrm{H}$, Chang AY, Kyer A, et al. Evaluation of generic medical information accessed via mobile phones at the point of care in resource-limited settings. J Am Med Inform Assoc 2014;21:37-42.

6 Patel RK, Sayers AE, Patrick NL, Hughes K, Armitage J, Hunter IA. A UK perspective on smartphone use amongst doctors within the surgical profession. Ann Med Surg 2015;4:107-12

7 Patel BK, Chapman CG, Luo N, Woodruff JN, Arora VM. Impact of mobile tablet computers on internal medicine resident efficiency. Arch Intern Med 2012:172:436-8.

8 Aungst TD, Clauson KA, Misra S, Lewis TL, Husain I. How to identify, assess and utilise mobile medical applications in clinical practice. Int J Clin Pract 2014:68:155-62.

9 Prgomet M, Georgiou A, Westbrook Jl. The impact of mobile handheld technology on hospital physicians' work practices and patient care: a systematic review. J Am Med Inform Assoc 2009; 16:792-801.

10 Franko OI, Tirrell TF. Smartphone app use among medical providers in ACGME training programs. J Med Syst 2012;36:3135-9.

11 Fan S, Radford J, Fabian D. A mixed-method research to investigate the adoption of mobile devices and Web2.0 technologies among medical students and educators. BMC Med Inform Decis Mak 2016:16:43.

12 Harris PA, Taylor R, Thielke R, Payne J, Gonzalez N, Conde JG. Research electronic data capture (REDCap) — a metadata-driven methodology and workflow process for providing translational research informatics support. J Biomed Inform 2009;42:377-81.

13 Ellaway RH, Fink $P$, Graves L, Campbell A. Left to their own devices: medical learners' use of mobile technologies. Med Teach 2014;36:130-8.

14 Wallace S, Clark M, White J. 'It's on my iPhone': attitudes to the use of mobile computing devices in medical education, a mixed-methods study. BMJ Open 2012;2:pii:e001099.

15 Siau K, Shen Z. Mobile healthcare informatics. Med Inform Internet Med 2006:31:89-99.

16 Baumgart DC. Smartphones in clinical practice, medical education, and research. Arch Intern Med 2011;171:1294-6.

17 Boulos MN, Wheeler S, Tavares C, Jones R. How smartphones are changing the face of mobile and participatory healthcare: an overview, with example from eCAALYX. Biomed Eng Online 2011;10:24.

18 Carter-Templeton HD, Wu L. Using mobile technologies to access evidence-based resources: a rural health clinic experience. Nurs Clin North Am 2015;50:595-603. 
19 BinDhim NF, Trevena L. There's an app for that: a guide for healthcare practitioners and researchers on smartphone technology. Online J Public Health Inform 2015;7: e218.

20 Eckleberry-Hunt J, Tucciarone J. The challenges and opportunities of teaching "generation y". J Grad Med Educ 2011;3:458-61.

21 Moreno-Walton L, Brunett P, Akhtar S, DeBlieux PM. Teaching across the generation gap: a consensus from the council of emergency medicine residency directors 2009 academic assembly. Acad Emerg Med 2009;16(Suppl 2): s19-24.
22 Freshwater ES, Crouch R. Technology for trauma: testing the validity of a smartphone app for pre-hospital clinicians. Int Emerg Nurs 2015;23:32-7.

23 Hawkes GA, Hawkes CP, Ryan CA, Dempsey EM. The demand for an educational smartphone app. Resuscitation 2013:84:e139.

24 Khanna RR, Wachter RM, Blum M. Reimagining electronic clinical communication in the post-pager, smartphone era. JAMA 2016;315:21-2.

25 Lee MK. Effects of mobile phone-based app learning compared to computer-based web learning on nursing students: pilot randomized controlled trial. Healthc Inform Res 2015;21:125-33. 